\title{
Quality Assessment of Randomized Control Trials Applied Psychotherapy for Chronic Pains in Iran: A Systematic Review of Domestic Trials
}

\author{
Fakhrudin Faizi ${ }^{1}$; Abbas Tavallaee ${ }^{1, *}$; Aboulfazl Rahimi ${ }^{2}$; Amin Saburi ${ }^{3}$; Masoud \\ Saghafinia ${ }^{4}$ \\ ${ }^{1}$ Behavioral Sciences Research Center, Baqiyatallah University of Medical Sciences, Tehran, IR Iran \\ ${ }^{2}$ Faculty of Nursing, Baqiyatallah University of Medical Sciences, Tehran, IR Iran \\ ${ }^{3}$ Chemical Injuries Research Center, Baqiyatallah University of Medical Sciences, Tehran, IR Iran \\ 4 Trauma Research Center, Department of Anesthesia, Baqiyatallah University of Medical Sciences, Tehran, IR Iran \\ *Corresponding Author: Abbas Tavallaee, Behavioral Sciences Research Center, Baqiyatallah University of Medical Sciences, Tehran, IR Iran. Tel: +98-2188053768, E-mail: tavresearch@ \\ gmail.com
}

Received: October 7, 2013; Revised: April 7, 2014; Accepted: January 8, 2014

\begin{abstract}
Context: Keeping in mind the burden of psychotherapy can play a crucial role concerning chronic pain (CP). Psychotherapy techniques are widely used to relief Chronic Pain (CP) worldwide. Appling psychotherapy needs to consider both individual and popular cultures. In addition to international requirements; nation-wide legitimacy should be regarded too. Psychological methods have provided a lot of articles in Iran, but they were neglected by the reviewers because the documents only have abstracts in English. The current study aimed to assess all Farsi Randomized Control Trials (RCTs) addressing psychotherapy to relieve chronic pains.

Evidence Acquisition: Six nation-wide medical databases were investigated in 2012 using the keyword chronic pain in the Abstracts, systematically. Appling PICO question format (patient problem or population, intervention, comparison, and outcomes) all the interventional studies were reviewed for eligibility. Retrieving full text (in Farsi) and making the articles indistinguishable, two native reviewers assessed the quality of the articles independently using Jadad scale.

Results: Inclusion criteria met 1542 abstracts. After refining and excluding, seventeen experimental studies were retrieved and evaluated. Mean quality score of Jadad was $1.53 \pm 1.37$ (median $=1.0$ ). Cognitive Behavior Therapy (CBT) was the dominant approach (11 out of 17$)$ and the majority (6 out of 17 studies) of the treated cases was Low Back Pain (LBP). Patient-therapist gender adjustment has clearly reported in most of the studies, based on the requirements.

Conclusions: Cognitive Behavior Therapy was more effective than the other psychotherapy approaches relieving chronic pain in the studies. Well-designed studies and comprehensive clarification of the studies demonstrating groups, intervention, follow-up and drop outs can improve the quality of the RCTs.
\end{abstract}

Keywords:Psychotherapy; Chronic Pain; Quality Assessment

\section{Context}

Intolerable burden of Chronic Pain (CP) in the machinery-living today (1-3), can be diminished. Psychotherapy methods can play a crucial role in management of chronic conditions. Nowadays; psychotherapy techniques are widely used to relieve all types of chronic pains worldwide $(4,5)$. Choosing appropriate techniques of psychotherapy not only depends on the client's condition, but also on the individual and popular culture (6). Besides international requirements, some countries have adopted nation-wide Codes and legitimacies that should be regarded in treatment setting. Many of psychotherapy methods are being used in Iran, and a lot of articles addressing psychotherapy have reported in local journals. However; the articles were neglected by the reviewers because the documents only have abstracts in English with- out providing full text. The non-commercially published papers usually contain useful information for health promotion (7). However access to the raw resource is challenging but useful and innovative (8). The number of the articles is growing considerably.

In the past decade (2002-2012); Iranian publications in the international journals have dramatically increased. Searching Pubmed database using Iran keyword in the [Tittle/Abstract] obviously reveals a twelve fold increase (1195.42\%) i.e. 393 records from 1993 to 2002 has risen to 4698 at the end of years 2003-2012. Meanwhile, national databases have been developed to publish the research documents. Gathering, analyzing and assessing quality of the RCTs and reporting the culture-bound results may help sharing experiences with the other researchers. 


\section{Evidence Acquisition}

A systematic review for the year 2012 was conducted using keywords of chronic pain and /or its Farsi keywords in the Abstract through the main national scientific and medical databases named Magiran (http://www. magiran.com), Iranmedex (http://www.irmedex.barakatkns.com/index.asp), Scientific Information Database (www.SID.ir), Irandoc (http://www.irandoc.ac.ir), Medlib (http://medlib.ir), and Yektaweb (http://yektaweb.com). After checking for duplication, all the abstracts concerning psychotherapy solely or in combination with the other treatment regiments for chronic pain were assessed using PICO format (Population, Intervention, Comparison, Outcome) (9). Observational studies and lor publications in the world-wide data bases were excluded. The process of searching, selecting, and recruiting the studies are shown in Figure 1. Authors' names, their affiliations, and the journal names were omitted. Peer-review process started and quality assessment of all retrieved full text articles in Farsi were examined independently by two reviewers using Jadad Scale as a reliable, valid, and specific scale in pain studies (10). The scale rates the quality of studies in the range of zero to five. Randomization, blindness and withdrawals/dropouts each were allocated one point and then, two additional points were added if the described randomization and dropout manner were appropriate. In case of discrepancy, the agreement was appointed by the third reviewer. Applied psychotherapy and the protocol are briefly presented in Table 1.

\section{Results}

A total of 17 experimental studies out of 1542 (treating 829 patients) were retrieved out of which eleven had pretest-posttest (six with controls), four parallel, and

Table 1. Applied Protocol of Psychotherapy for Chronic Pain ${ }^{a}$

\begin{tabular}{|c|c|}
\hline Reference & Protocols for Chronic Pain \\
\hline Pouladi et al. (11) & PMR $^{b}$, Stimulus control ${ }^{c}$ and Stress Inoculation ${ }^{d}: 45-60$ minutes for eight sessions. \\
\hline Khanzadeh et al. (12) & Massage + exercise: 60 minutes three times a week for eight weeks (total $=24 \times 60$ minutes) \\
\hline Khezri et al. (13) & Hypnotism 60 minutes for nine sessions \\
\hline Akbari and Forough (14) & $\begin{array}{l}\text { APS: warm pad } 20 \text { minutes, APS } 16 \text { min then activity up to tolerance; TENS: warm pad } 20 \text { min, TENS } \\
16 \text { minutes, and activity up to tolerance for } 10 \text { sessions. }\end{array}$ \\
\hline Rafiee et al. (15) & CBT: 50 minutes for eight sessions, follow-up to one month. \\
\hline Shaban et al. (16) & PMR: 30 minutes for three days, Music therapy: 30 min for three days \\
\hline Abbasi et al. (17) & $\begin{array}{l}\text { Spouse-Assisted educational Package and or patient-oriented education (without spouse support): } \\
\text { two hours per a week for seven sequential weeks. }\end{array}$ \\
\hline
\end{tabular}

Mohammadi et al. (18)

Mindfulness-based Cognitive therapy: two hours in a week for two month.

Rahimian (19)

CBGT: 90 minutes per a week for eight sequential weeks. Follow-up to four months.

Golchin et al. (20)

CBT: 90 minutes per a week for twelve sequential weeks.

Nadjafi Ghezeljeh et al. (21)

Massage: 10 minutes (five minutes for each foot) for three consecutive days.

Yousefi Nejad et al. (22)

Music therapy: for three days and then pain intensity measuring.

Gharaie et al. (23)

ACT: 60 minutes a week for eight consecutive sessions.

Sadoughi et al. (24)

CBT (Stress Management Training) then apprising headache in frequency, severity and duration using Headache Diary).

Alavi et al. (25)

Momen et al. (26)

Vakili et al. (27)
Hypnotism: three to seven sessions and then follow-up for three months.

PMR: two times (10 minutes) a day for a month and then follow-up for two months.

CBPMT: 8 sessions in eight consecutive weeks and follow-up for two months.

${ }^{\mathrm{a}}$ Abbreviations: ACT, acceptance and commitment therapy; APS, action potential stimulation; CBT, cognitive behavior therapy; CBGT, cognitivebehavioral group therapy; CBT, cognitive behavior therapy; CBPMT, cognitive behavior pain management therapy; PMR, progressive muscle relaxation.

b Jacobson (1962).

${ }^{\mathrm{C}}$ Kanfer (1985).

$\mathrm{d}_{\text {Michenbaum \& Turk (1976). }}$ 
two cross-over designs. Only one study obtained full points (five score). Mean score of Jadad was $1.53 \pm 1.37$ (median $=1.0)$. Details of quality assessment of the RCTs are summarized in Table 2. There were six studies on Low Back Pain, the majority, four studies on Tension Headache (TH), four Musculoskeletal pain (MSP), and one cancer pain. Cognitive Behavior Therapy (CBT) had been applied in 11 out of 17 studies in patients with different conditions as LBP (four studies), MSP (four studies), TH (two studies) and cancer pain (one study). Two studies reported music therapy and massage for cancer pain, emphasizing that foot massage was more effective in terms of increasing relaxation and lowering pain intensity $(\mathrm{P}<0.0001)$. One study (16) which had compared CBT and music therapy for cancer pain reported that PMR was more effective $(P<0.01)$. Table 3 presents more information and clarifies differences of the studies. One parallel study (17) used combination of family therapy and interpersonal therapy for LBP named Spouse-Assisted Multidisciplinary Pain Management Program (SA-
MPMP) versus Patient-Oriented Multidisciplinary Pain Management Program (P-MPMP) reported significant reduction in Kinesiophobia (patient) and lesser spouse's negative response to activity $(\mathrm{P}=0.05)$. The two methods not only significantly decreased depression, anxiety, stress, disability, and pain, but also increased marital adjustment in comparison to the baseline. Besides, the positive outcomes of the two methods, the spouse's stress, anxiety, and depression rose as a negative outcome in SA-MPMP method. Hypnotism as a psychodynamic psychotherapy was applied in the two studies for patients with tension-type headaches (13, 25). Despite the low quality of articles (Jadad score zero and one); both articles reported significant reduction in pain occurrence and consumption of analgesics. The notable finding was that nine studies $(11,27)$ clearly reported that both the therapists and the patients were the same sex. The patient's or therapist's gender were not directly mentioned in the rest (eight studies). Female patients should be treated only by female therapists based on the local rules.

Table 2. Quality Assessment: Jadad Score for Iranian Randomized Control Trials a

\begin{tabular}{|c|c|c|c|c|c|c|}
\hline \multirow[t]{2}{*}{ References } & \multicolumn{2}{|c|}{ Randomization } & \multicolumn{2}{|c|}{ Double Blinding } & \multirow[t]{2}{*}{ Drop-Outs } & \multirow[t]{2}{*}{ Total Score } \\
\hline & Randomized & $\begin{array}{l}\text { Appropriate } \\
\text { and Reported }\end{array}$ & Double-blind & $\begin{array}{c}\text { Appropriate } \\
\text { and Reported }\end{array}$ & & \\
\hline Pouladi et al. (11) & 1 & 1 & 0 & 0 (NR) & $0(N R)$ & 2 \\
\hline Khanzadeh et al. (12) & $0(N R)$ & 1 & 0 & $0(\mathrm{NR})$ & 1 & 2 \\
\hline Khezri et al.(13) & $0(N R)$ & $0(N R)$ & 0 & $0(\mathrm{NR})$ & $0(N R)$ & 0 \\
\hline Akbari et al. (14) & $0(N R)$ & $0(\mathrm{NR})$ & 0 & $0(\mathrm{NR})$ & 1 & 1 \\
\hline Rafiee et al. (15) & $0(N R)$ & 0 (NR) & 0 & $0(\mathrm{NR})$ & $0(N R)$ & 0 \\
\hline Shaban et al. (16) & 1 & 1 & 0 & $0(\mathrm{NR})$ & $0(N R)$ & 2 \\
\hline Abbasi et al. (17) & 1 & 1 & 1 & $0(\mathrm{NR})$ & 1 & 4 \\
\hline Mohammadi et al. (18) & 0 & 1 & 0 & 0 (NR) & $0(N R)$ & 1 \\
\hline Rahimian et al. (19) & 1 & 1 & 1 & 1 & 1 & 5 \\
\hline Golchin et al. (20) & 1 & 1 & 0 & $0(\mathrm{NR})$ & $0(N R)$ & 2 \\
\hline Nadjafi Ghezeljeh et al. (21) & 1 & 1 & 0 & $0(\mathrm{NR})$ & $0(N R)$ & 2 \\
\hline Yousefinejad et al. (22) & $0(\mathrm{NR})$ & $O(N R)$ & 0 & $0(\mathrm{NR})$ & $0(N R)$ & 0 \\
\hline Gharaie et al. (23) & 0 & 1 & 0 & $\mathrm{O}(\mathrm{NR})$ & $0(N R)$ & 1 \\
\hline Sadoughi et al. (24) & 0 & 1 & 0 & $0(\mathrm{NR})$ & $0(\mathrm{NR})$ & 1 \\
\hline Alavi et al. (25) & $0(N R)$ & $\mathrm{O}(\mathrm{NR})$ & 0 & $0(\mathrm{NR})$ & 1 & 1 \\
\hline Momen et al. (26) & $0(N R)$ & 0 (NR) & 0 & $0(\mathrm{NR})$ & $0(N R)$ & 0 \\
\hline Vakili et al. (27) & 1 & 1 & 0 & $0(\mathrm{NR})$ & $0(\mathrm{NR})$ & 2 \\
\hline
\end{tabular}

a Abbreviations: NR, not reported; NA, not appropriate. 
Faizi F et al.

\begin{tabular}{|c|c|c|c|c|c|c|c|c|c|c|}
\hline 芯 & 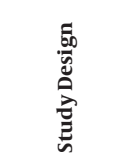 & 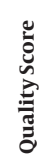 & 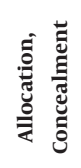 & 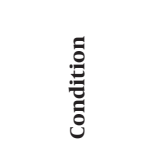 & ڤ్ & 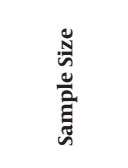 & 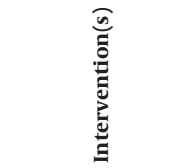 & 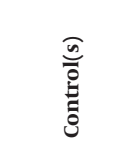 & 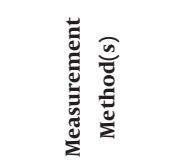 & 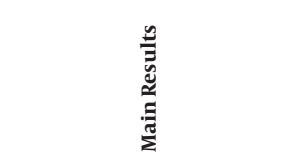 \\
\hline Pouladi et al.(11) & RCT & (2) & No & LBP & Male & $100(4 * 25)$ & $\begin{array}{c}\text { Cognitive } \\
\text { therapy(Stress } \\
\text { Inoculation), } \\
\text { Behavior } \\
\text { therapy(Stimulus } \\
\text { Control), Relax- } \\
\text { ation (PMR) }\end{array}$ & SC; Baseline & $\begin{array}{c}\text { PBPI, PBQ, PSEQ, } \\
\text { BDI, MPI-F }\end{array}$ & $\begin{array}{l}\text { Cognitive therapy and PMR } \\
\text { improved pain beliefs and } \\
\text { behaviors }(\mathrm{P}=0.01) \text { more } \\
\text { than behavior therapy, Pain } \\
\text { Self-Efficiency enhanced } \\
(\mathrm{P}=0.001) \text { and depression } \\
\text { decreased }(\mathrm{P}=0.001) \text { in } \\
\text { all intervention groups in } \\
\text { comparison to controls. }\end{array}$ \\
\hline $\begin{array}{l}\text { Khanzadeh et } \\
\text { al.(12) }\end{array}$ & RCT & (3) & Yes & LBP & Male & $30(2 * 15)$ & $\begin{array}{c}\text { Combined } \\
\text { Exercise therapy, \& } \\
\text { Massage }\end{array}$ & SC & $\begin{array}{l}\text { VAS, Physical } \\
\text { Activity }\end{array}$ & $\begin{array}{l}\text { Pain score lowered }(2.85 \pm \\
1.8, \mathrm{P}=0.003) \text { and Physical } \\
\text { Performance improved ( } 31.41 \\
\pm 3.14, \mathrm{P}=0.002)\end{array}$ \\
\hline Khezri et al.(13) & RCT(MBD) & (0) & No & TH & $\mathrm{NR}$ & 3 & Hypnotism & Baseline & VAS, BDI & $\begin{array}{l}\text { Decreased Pain Intensity and } \\
\text { Anxiety after intervention } \\
\text { and after one month follow- } \\
\text { up comparing base line. }\end{array}$ \\
\hline $\begin{array}{l}\text { Akbari and For- } \\
\text { ough (14) }\end{array}$ & RCT & (1) & No & Osteoarthritis & $\begin{array}{c}\text { Male and } \\
\text { Female }\end{array}$ & $32(16+16)$ & $\begin{array}{l}\text { APS, (Female); } \\
\text { TENS, (Male and } \\
\text { Female) }\end{array}$ & Baseline & VAS & $\begin{array}{l}\text { No significant differences } \\
\text { between two groups. Each } \\
\text { stage had significant im- } \\
\text { provement comparing other } \\
\text { stages in each group (ANOVA, } \\
\qquad \mathrm{P}<0.05 \text { ). }\end{array}$ \\
\hline Rafiee et al. (15) & RCT(MBD) & (0) & No & CP (MSP) & $\begin{array}{c}\text { Male and } \\
\text { Female }\end{array}$ & 4 & CBT & Baseline & $\begin{array}{l}\text { VAS, BDI, PCS, } \\
\text { CCSI }\end{array}$ & $\begin{array}{l}\text { CBT reduced depression, } \\
\text { pain intensity, catastroph- } \\
\text { izing, and improved coping } \\
\text { strategies in the follow up, } \\
\text { The effects were maintained } \\
\text { to some extent }\end{array}$ \\
\hline
\end{tabular}

\begin{tabular}{|c|c|c|c|c|c|c|c|c|c|c|}
\hline Shaban et al. (16) & RCT & (2) & yes & Cancer pain & $\begin{array}{l}\text { Male and } \\
\text { Female }\end{array}$ & $100(50+50)$ & $\begin{array}{l}\text { PMR, Music } \\
\text { therapy }\end{array}$ & Baseline & VAS & $\begin{array}{l}\text { Pain } \downarrow \text { significantly in both } \\
\text { groups comparing baseline } \\
(\mathrm{P}<0.001) \text {. PMR was more } \\
\text { effective than Music therapy } \\
\quad(\mathrm{P}<0.016) .\end{array}$ \\
\hline Abbasi, et al. (17) & RCT & (4) & Yes & LBP & $\begin{array}{l}\text { Male and } \\
\text { Female }\end{array}$ & $24(12+12)$ & $\begin{array}{c}\text { SA-MPMP, Vs; } \\
\text { P-MPMP }\end{array}$ & Baseline & $\begin{array}{c}\text { RDQ, VAS, DASS, } \\
\text { TSK, SRI, MAT }\end{array}$ & $\begin{array}{l}\text { SA-MPMP } \downarrow \text { kinesiophobia } \\
\text { and spouse negative re- } \\
\text { sponse to activity comparing } \\
\text { P-MPMP }(\mathrm{P}=0.05) \text {. Pre and } \\
\text { Post comparison showed } \\
\text { significant } \downarrow \text { in depression, } \\
\text { anxiety, stress, disability, } \\
\text { pain, and } \uparrow \text { marital adjust- } \\
\text { ment (patient). Increased the } \\
\text { spouses' stress, anxiety and } \\
\text { depression. }\end{array}$ \\
\hline
\end{tabular}

\begin{tabular}{|c|c|c|c|c|c|c|c|c|c|c|}
\hline $\begin{array}{l}\text { Mohammadi et } \\
\text { al.(18) }\end{array}$ & RCT & (1) & Yes & CP (MSP) & Female & $30(2 * 15)$ & MBCT & SC, Baseline & GPQ, RDQ & $\begin{array}{l}\text { MBCT reduced severity of } \\
\text { pain }(\mathrm{P}<0.002) \text { and lowered } \\
\text { disability comparing con- } \\
\text { trols }(\mathrm{P}<0.00) \text {. }\end{array}$ \\
\hline Rahimian (19) & RCT & (5) & Yes & LBP & $\begin{array}{c}\text { Male and } \\
\text { Female }\end{array}$ & $35(13+12)^{b}$ & CBGT & Baseline & MPI-F & $\begin{array}{l}\text { Mean pain score } \downarrow \text { signifi- } \\
\text { cantly after intervention in } \\
\text { comparison to controls and } \\
\text { baseline. }(\mathrm{P}<0.03) \text {. Power } \\
\text { of the study reported as } 1\end{array}$ \\
\hline
\end{tabular}


Faizi F et al.

\begin{tabular}{|c|c|c|c|c|c|c|c|c|c|c|}
\hline $\begin{array}{l}\text { Golchin et al. } \\
\text { (20) } 111\end{array}$ & RCT & (2) & NO & CLBP & Female & $30(2 * 15)$ & CBT & SC, Baseline & QBPDS, WOC & $\begin{array}{l}\text { Scores of experimental indi- } \\
\text { viduals } \downarrow \text { significantly in all } \\
\text { the subscales of maladaptive } \\
\text { coping, back pain, and } \uparrow \text { in } \\
\text { all the subscales of adaptive } \\
\text { coping compared with } \\
\text { control group }(\mathrm{P}<0.05) \text {. }\end{array}$ \\
\hline $\begin{array}{l}\text { Nadjafi Ghezeljeh } \\
\text { et al. (21) } 112\end{array}$ & RCT & 3 Group & 2) & Chronic Pain & Female & 75 & $\begin{array}{c}\text { Foot Massage and } \\
\text { Relaxation }\end{array}$ & $\begin{array}{l}\text { Cross-over, } \\
\text { Baseline }\end{array}$ & VAS & $\begin{array}{l}\text { Significant } \uparrow \text { relaxation and } \\
\downarrow \text { pain intensity }(\mathrm{p}<0.0001) \text {. } \\
\text { There were also statistically } \\
\text { significant differences in } \\
\text { variables trends of change (p } \\
<0.0001) \text {. }\end{array}$ \\
\hline
\end{tabular}

\begin{tabular}{|c|c|c|c|c|c|c|c|c|c|c|}
\hline $\begin{array}{l}\text { Yousefi Nejad et } \\
\text { al.(22) }\end{array}$ & RCT & (2) & No & Cancer Pain & $\begin{array}{l}\text { Male and } \\
\text { Female }\end{array}$ & $40(2 * 20)$ & Music therapy & $\begin{array}{l}\text { Cross-over, } \\
\text { Baseline }\end{array}$ & VAS & $\begin{array}{l}\text { Pain in stages of pre and } \\
\text { post-implementation of } \\
\text { music therapy showed } \\
\text { significant differences on the } \\
\text { basis of variables including } \\
\text { age, sex, duration and the } \\
\text { type of tissue involved ( } \mathrm{a}= \\
5 \%, \mathrm{Z}=1.645) \text {. }\end{array}$ \\
\hline $\begin{array}{l}\text { Gharaie Ardekani } \\
\text { et al. (23) }\end{array}$ & RCT & (2) & Yes & $\mathrm{TH}$ & Female & $30(2 * 15)$ & $\mathrm{ACT}$ & SC, Baseline & VAS, CPAQ & $\begin{array}{l}\text { Acceptance and Com- } \\
\text { mitment Therapy caused } \\
\text { significant reduction in pain } \\
\text { intensity }(\mathrm{P}<0.001) \text {. }\end{array}$ \\
\hline $\begin{array}{l}\text { Sadoughi et al. } \\
\text { (24) } 115\end{array}$ & RCT & (1) & Yes & $\mathrm{TH}$ & Female & $38(18+20)$ & CBT + Drug & SC (Drug) & Headache Diary & $\begin{array}{c}\text { Significant differences be- } \\
\text { tween experimental and con- } \\
\text { trol groups in the frequency } \\
(\mathrm{P}<0.01) \text {, intensity }(\mathrm{P}<0.05) \\
\text { and duration }(\mathrm{P}<0.001) \text { of } \\
\text { headache attacks. }\end{array}$ \\
\hline Alavi et al. (25) & RCT & (1) & No & $\mathrm{TH}$ & $\begin{array}{l}\text { Male and } \\
\text { Female }\end{array}$ & 30 & Hypnotism & Baseline & VAS & $\begin{array}{l}\text { Comparison to baseline; } 33 \% \\
\text { reported no headache, } 13 \% \\
\text { not effective and } 20 \% \text { allevi- } \\
\text { ated. The days of treatment } \\
\text { for analgesic } \downarrow \text { significantly. }\end{array}$ \\
\hline Momen et al. (26) & RCT & (0) & Yes & MPDS & $\begin{array}{l}\text { Male and } \\
\text { Female }\end{array}$ & $33(8+25)$ & PMR & Baseline & VAS & $\begin{array}{l}\text { Comparison to baseline; in- } \\
\text { tensity of pain, tenderness of } \\
\text { masticatory muscles, maxi- } \\
\text { mum opening of mouth with } \\
\text { and without pain, anxiety ( } \mathrm{P} \\
<0.001 \text { ) and depression }(\mathrm{P}= \\
\text { 0.001) improved significantly } \\
\text { after treatment. }\end{array}$ \\
\hline Vakili et al. (27) & RCT & $(2)$ & NO & $\begin{array}{l}\text { LBP and } \\
\text { Anxiety }\end{array}$ & Female & 24 & СВРMT & $\begin{array}{l}\text { SC (Drug), } \\
\text { Baseline }\end{array}$ & SCL-90-RBDI & $\begin{array}{c}\text { Experimental group had low } \\
\text { depression in comparison } \\
\text { to baseline }(\mathrm{P}<0.02) \text { and } \\
\text { controls }(\mathrm{P}<0.001) \text {. They also } \\
\text { reported lower depression } \\
\text { than controls after two } \\
\text { months of follow-up }(\mathrm{P}< \\
0.004) \text {. }\end{array}$ \\
\hline
\end{tabular}

a Abbreviations: ACT, acceptance and commitment therapy; APS, action potential stimulation; BDI, beck depression inventory; CBGT, cognitivebehavioral group therapy; CBPMT, cognitive behavior pain management therapy; CBT, cognitive behavior therapy; CCSI, cognitive coping strategies inventory; CP, chronic pain; CPAQ, chronic pain acceptance questionnaire; DASS42, depression-anxiety-stress scale; GPQ, graded pain questionnaire; LBP, low back pain; MAT, marital adjustment scale; MBCT, mindfulness-based cognitive therapy; MBD, multiple baseline design; MPI-F, multi-dimensional pain inventory-farsi (ASGHARI MOGHADAM-2008); MPDS, myofascial pain dysfunction syndrome; MSP, musculoskeletal pain; PBPI, pain beliefs and perception inventory; PBQ, pain behavior questionnaire; PCS, pain catastrophizing scale; PMR, progressive muscle relaxation; P-MPMP, patient-oriented multidisciplinary pain management program; PSEQ, pain self-efficiency questionnaire; QBPDS, quebec back pain disability scale; QDS, quebec disability scale; RCT, randomized controlled trial; RDQ, roland-morris disability questionnaire; SA-MPMP, spouse-assisted multidisciplinary pain management program; SC, standard care, SCL90-R, symptom checklist 90-revised; SF-36, short form quality of life 36; SRI, spouse response inventory; TH, tension headache; TENS, trans electrical nerve stimulation; TSK, tampa scale for kinesiophobia; VAS, visual analog scale; WOCQ, ways of coping questionnaire. $\mathrm{b}$ Intervention group divided to male (12) and female (11) due to cultural conservation. 


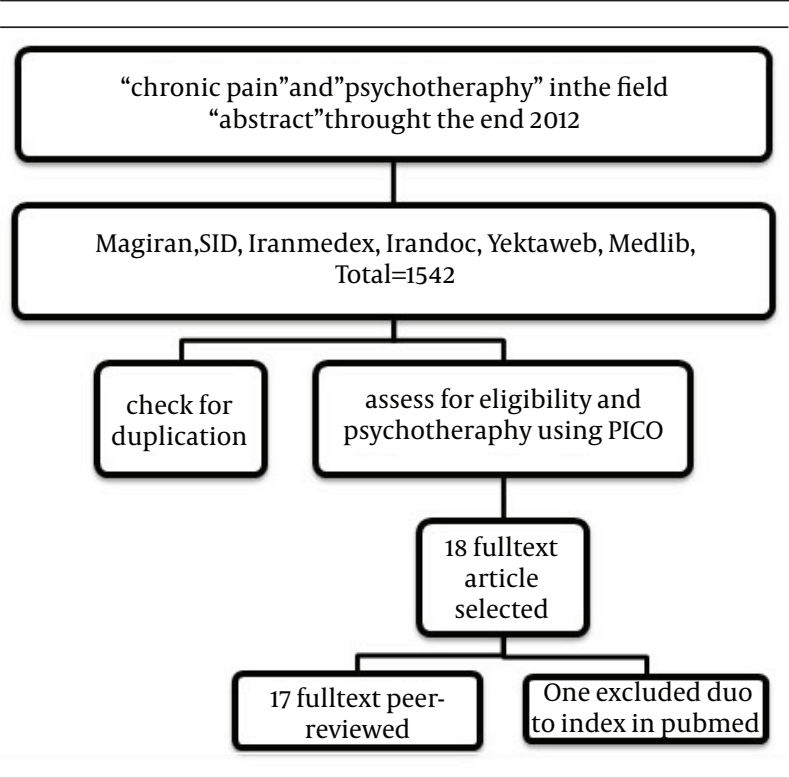

Figure 1. Tracking and Enrollment of RCTs

\section{Discussion}

According to Barrett's definition, which is: "relaxation methods include deep breathing, imagery, massage and music therapy" (28), nine studies used the relaxation techniques one by one or thorough interdisciplinary programs. According to many documents, relaxation techniques play an incredible role in psychological therapy of chronic pain leaving muscular and vegetative stabilization along with the interruption of pain cycle (29). Chronic LBP was the most prevalent patient condition in the review, and CBT was applied as a choice psychotherapy method but the mean score was 2.33. CBT was also the most dominant applied approach (11 out of 17) to overcome chronic pain in the review. According to Lin and Vaska, each country can use cognitive behavioral therapy approach to develop local educational programs enriching its gray literature (30). Considering the affected psychological functioning in chronic pain such as LBP (31), CBT has proved to be a useful approach dealing with both cognitive therapy and behavioral manipulation. One study (18) applied mindfulness-based cognitive therapy for chronic pain and reported positive effects. The usefulness of the technique in chronic pain was mentioned before (32) but the limitation here was that only female subjects were recruited in the pre- and post-test study. Based on Jadad Scale, every RCT should acquire at least two points to enter quality assessment (33), regarding the low quality of the assessed articles, they had not been entered into any reviews before. It is time to mention that most of the articles in the country are provided by students or junior researchers and then edited by faculty members. Unfortunately, students may forget to comprehensively describe their research methodology leaving the reports to be categorized as low quality regarding standard quality assessment tools. In fact, any Ph.D. or M.Sc. thesis and/ or research proposals should be carefully assessed before application by a Research Counsel in Deputy of Research organized in universities countrywide. The research reports can be published only if they are supervised regarding all the standards during implementation. A remarkable difference that should be mentioned here is the National Adaptation Code (Tarh-e-Intebagh) adopted in 1998. Based on the code, every treatment on a patient should be done only by a therapist with the same sex of the patient. In conclusion, all female patients should be treated by female therapists. The code has flexibility in some situations like human resource stricture. This new approach can minimize all therapeutic misconducts and improve patient-therapist relation. Same patient-same therapist proposal was recommended to improve patients' rights and protect them through legal prohibition from psychotherapeutic misconduct (34).

Psychotherapy is applied to relieve chronic pain as a predominant technique in Iran. Therapists applied CBT as an effective technique more than the other types of psychotherapy to overcome chronic pain. The current study reflects country-wide conformity between the applied techniques and population's culture under legitimate rules. Keeping in mind the low quality trials in the review; it is recommend that well-designed RCTs with rigorous methodology can offer better view of psychotherapy.

\section{Acknowledgements}

Authors wish to offer their special thanks to Dr. Khodabakhsh Ahmadi, Director of Behavioral Science Research Center, for his guidance and financial supports. Authors also wish to sincerely thank all the personnel of the research center for their quick responsiveness during the review.

\section{Funding/Support}

The review was done by financial supports from Behavioral Sciences Research Center of Baqiyatallah University of Medical Sciences.

\section{References}

1. Langley PC. The societal burden of pain in Germany: health-related quality-of-life, health status and direct medical costs. J Med Econ. 2012;15(6):1201-15.

2. Kanzler KE, Bryan CJ, McGeary DD, Morrow CE. Suicidal ideation and perceived burdensomeness in patients with chronic pain Pain Pract. 2012;12(8):602-9.

3. Kurita GP, Sjogren P, Juel K, Hojsted J, Ekholm O. The burden of chronic pain: a cross-sectional survey focussing on diseases, immigration, and opioid use. Pain. 2012;153(12):2332-8.

4. Donatone B. Focused suggestion with somatic anchoring technique: rapid self-hypnosis for pain management. Am J Clin Hypn. 2013;55(4):325-42.

5. Slavin-Spenny O, Lumley MA, Thakur ER, Nevedal DC, Hijazi AM. Effects of anger awareness and expression training versus relaxation training on headaches: a randomized trial. Ann Behav Med. 2013;46(2):181-92.

6. de Figueiredo JM, Gostoli S. Culture and demoralization in psychotherapy. Adv Psychosom Med. 2013;33:75-87.

7. Turner AM, Liddy ED, Bradley J, Wheatley JA. Modeling public 
Faizi F et al.

health interventions for improved access to the gray literature. $J$ Med Libr Assoc. 2005;93(4):487-94.

8. Pappas C, Williams I. Grey literature: its emerging importance. Hosp Librariansh. 2011;11(3):228-34.

9. Elkins MY. Using PICO and the brief report to answer clinical questions. Nursing. 2010;40(4):59-60.

10. Clark HD, Wells GA, Huet C, McAlister FA, Salmi LR, Fergusson D, et al. Assessing the quality of randomized trials: reliability of the Jadad scale. Control Clin Trials. 1999;20(5):448-52.

11. Pouladi Reishahri AK, Najarian B, Shokrkon H, Mehrabizadeh M. Evaluation of the effectiveness of Cognitive, Relaxation and Behavior therapy on chronic low back pain in male teachers of Ahvaz. JEduc Psychol. 2001;3(1):49-72.

12. Khanzadeh R, Hashemi Javaheri AA, Omidi Kashani F, Zandi M, Khodabakhshi M. The Effect of Combined Therapeutic Protocol (Therapeutic Exercises and Massage) on the Pain and Physical Performance in Men with Chronic Low Back Pain Due to Lumbar Disc Herniation. Evid Based Care. 2012;2(2):29-36.

13. Khezri N, Baniasadi H, Kahrazehi F. An Evaluation of Hypnotherapy Efficacy In The Treatment of Chronic Tension Headache. J Educ Psychol Stud. 2007(3).

14. Akbari M, Forough B. Comparison of the Effect of APS and TENS in Reduction of Pain and Functional Improvement of Patients with Mild to Moderate Osteoarthritisof Knee. Univ Med Sci IRAN. 2005;3(12):659-63.

15. Rafiee S, Sohrabi F, Shams J, Forough AA. The efficacy of Cognitive Behavioral Therapy in patients with chronic musculoskeletal pain. JJahrom Univ Med Sci. 2012;10(19).

16. Shaban M, Rasoolzadeh N, Mehran A, Moradalizadeh F. Study of two non-pharmacological methods, progressive muscle relaxation and music, on pain relief of cancerous patients. Hayat. 2006;12(3):63-72.

17. Abbasi M, Dehghani M, Jafari H, Behtash H, Shams J, Panaghi L. Comparing Two Chronic Low Back Pain Intervention Models: Spouse-Assisted vs. Patients-Oriented.J Fam Res. 2012;8(30):191-211.

18. Mohammadi F, Mohammadkhani P, Dolatshahi B, Asghari MA The effects of "mindfulness meditation for pain management" on the severity of perceived pain and disability in patients with chronic pain. Iran J Ageing. 2011;6(19).

19. Rahimian Boogar B. The Effect of Cognitive-Behavioral Group Therapy on Improving the Multidimensional Pain Symptoms of the Patients with Chronic Low Back Pain.J Army Univ Med Sci Iran. 1390;9(3):19.

20. Golchin N, Janbozorgi M, Alipour A, Agah-Heris M. The Efficacy of Cognitive Behavioral Therapy on Using Coping Strategies and Decreasing Pain Among Females With Chronic Back Pain. J Fun- damentals Ment Health. 2011;13(2):160-9.

21. Nadjafi Ghezeljeh T, Rahimiha F, Mohaddes Ardebili F, Hosseini F Effect of Foot Massage on Relaxation and Pain Intensity of Cancer Patients. Iran J Nurs. 2002;15(32):75-82.

22. Yousefi Nejad ostad Kelayeh A, Madadi A, Majd Zadeh SR, Shaban Nia R, Sadeghian N, Zarin Ara AR. The Effect of Music Therapy on Chronic Pain in Patients With Cancer. J Qazvin Univ Med Sci. 2005;9(1):39-42.

23. Gharaie Ardekani S, Azad Fallah P, Tavallaie A. The Effectiveness of Acceptance and Commitment Therapy on Pain Experience in Women with Chronic Pain.J Clin Psychol. 2012;4(2):39-50.

24. Sadoughi M, Akkashe G. Effectiveness of Cognitive-Behavioral Therapy on Reduction of Chronic Tension Headache. J Shahrekord Univ Med Sci. 2009;11(3):85-92.

25. Alavi SM, Mahjoubifard M, Lashkaripour K, Fathi M. Evaluation of the Effect of Hypnosis on the Treatment of Tention Headache. $J$ Iran Soci Anaestesiology Intensive Care. 2003;23(42):22-5.

26. Momen Beitollahi J, Sahebjamie M, Manavi A, Farrokhnia T, Zohiroddin A, Golestan B. Effect of Progressive Muscle Relaxation Therapy on Improving Signs and Symptoms of Patients with myofacial pain Dysfunction Syndrome.J Dent Med. 2009;21(4):249-54.

27. Vakili N. The Effect of Cognitive-Behavioral Group Pain Management Therapy on Depression of the Female with Chronic Low Back Pain.J Clin Psychol. 2009;1(4):11-9.

28. Barrett AM. Pain in the Elderly . In: Wittink H, Hoskins Michel T editors. Chronic pain management for physical therapists: British Library Cataloguing-in-Publication Data; 2002. pp. 247-55.

29. Diezemann A. [Relaxation techniques for chronic pain]. Schmerz 2011;25(4):445-53.

30. Lin Y, Vaska M. Raising awareness of grey literature in an academic community using the cognitive behavioral theory. Grey $\mathrm{J}$. 2010;6(2):57-63.

31. Janowski K, Kuryłowicz J, Steuden S. Psychosocial Functioning Questionnaire for Patients with Low Back Pain: development and psychometric properties. Arch Med Sci . 2005;1(3):157-62.

32. Flugel Colle KF, Vincent A, Cha SS, Loehrer LL, Bauer BA, WahnerRoedler DL. Measurement of quality of life and participant experience with the mindfulness-based stress reduction program. Complement Ther Clin Pract. 2010;16(1):36-40.

33. Jadad AR, Moore RA, Carroll D, Jenkinson C, Reynolds DJ, Gavaghan DJ, et al. Assessing the quality of reports of randomized clinical trials: is blinding necessary? Control Clin Trials. 1996;17(1):1-12.

34. Riemer M, Schneider G. [Improving prevention of sexual abuse by therapists during ongoing psychotherapeutic or psychiatric treatment]. Z Psychosom Med Psychother. 2006;52(4):406-24. 